\title{
Endometrial stromal sarcoma: a rare tumour
}

\section{Amrit Pal Kaur*, Harbhajan Kaur Shergill}

Department of Obstetrics \& Gynaecology, Govt. Medical College, Amritsar, Punjab, India

Received: 26 January 2014

Accepted: 02 February 2014

\section{*Correspondence:}

Dr. Amrit Pal Kaur,

E-mail: amritdhillon63@msn.com

(C) 2014 Kaur AP et al. This is an open-access article distributed under the terms of the Creative Commons Attribution Non-Commercial License, which permits unrestricted non-commercial use, distribution, and reproduction in any medium, provided the original work is properly cited.

\begin{abstract}
Endometrial stromal sarcomas (ESS) are rare endometrial tumours arising from stroma of endometrium i.e. connective tissue of endometrium rather than glands. Usually a pre-operative diagnosis is difficult. Total abdominal hysterectomy with bilateral salpingo-oophorectomy is main line of treatment. Adjuvant hormone therapy in the form of progesterones, GnRH analogues, aromatase inhibitors are effective for prevention of recurrences as these tumours are invariably positive for oestrogen $\&$ progesterone receptors. Surgical excision, radiotherapy, hormone therapy are recommended for recurrences. We report a 52 yrs widow with undifferentiated endometrial stromal sarcoma weighing $3.75 \mathrm{~kg}$ with a short history of 3 months diagnosed only after histopathology.
\end{abstract}

Keywords: Endometrial stromal sarcoma, Malignant uterine tumour, Uterine Sarcoma

\section{INTRODUCTION}

Endometrial stromal sarcomas (ESS) are very rare malignant tumours that make around $0.2 \%$ of all uterine malignancies. They resemble endometrial stromal cells in the proliferative stage. The annual incidence of ESS is 12 per million women. Compared to other uterine malignancies, ESS affects younger women and the mean age is 42 to 58 years. $^{1}$ They account for less than $10 \%$ of the uterine mesenchymal neoplasm and 10 to $25 \%$ of affected women are premenopausal. ESS is an indolent tumour with local recurrences and distant metastasis can occur even 20 years after initial diagnosis.

\section{CASE REPORT}

A 52 years old widow, postmenopausal for the last 2 years, P1L1A1 with previous one caesarean presented with symptoms of abdominal distension, pain lower abdomen, increased frequency of micturition, decreased appetite and generalized weakness for 3 months and constipation for one month. On general physical examination, she was poorly nourished with moderate anemia.

Abdominal examination revealed a solid mass of 34 week size, superiorly reaching up to epigastrium, laterally to the flanks. Lower edge could not be reached. It was dull on percussion and no shifting dullness was present. On per vaginal examination, solid firm mass felt in posterior fornix. Uterus could not be felt separately from the mass. Cervix was pin pointed and placed anteriorly. Per rectal examination revealed rectal mucosa free, mass felt anteriorly.

Her blood investigations revealed anemia, with $\mathrm{Hb}$ $8 \mathrm{gm} \%$.Liver function, Kidney function tests were within normal limits. CA125 was 144.06 IU/l. X ray chest normal. Ultrasound showed $23 \times 17 \mathrm{~cm}$ solid mass showing heterogenous echotexture arising from pelvis and extending into abdomen. Uterus could not be visualized separately. CT scan showed heterogenous enhancing mass in pelvis measuring $14 \times 22 \times 27 \mathrm{~cm}$. Uterus and adnexa could not be separately defined from this mass. Mass was displacing the gut loops and causing 
compression of urinary bladder. FNAC showed malignant mesenchymal tumour. Patient was built up for surgery, counselling done. Thinking it to be an ovarian mass patient was taken for exploratory laparotomy.

Per operatively large, solid, highly vascular, lobulated mass with irregular margins and areas of necrosis, size about $30 \times 25 \mathrm{~cm}$, extending up to xiphisternum, laterally extending upto flanks, inferiorly reaching pelvis was seen. The posterior surface of tumour was adherent to gut and omentum. Peritoneal washings taken. Inspection of abdominal cavity was done for locating any possible sites of metastasis. Pelvic lymph nodes were palpated and not found to be enlarged. Omentum was carefully inspected and no gross pathology was found. Posterior surface of uterus \& right ovary was normally looking (Figure 1). Tumour was arising from left anterior wall of uterus encasing left normal looking ovary, extending upwards into abdomen. Uterus, cervix, bilateral tubes \& ovaries with whole of mass were removed. Omental biopsy taken. As the tumour was highly vascular, considering operative time \& general condition of the patient, lymphadenectomy was not done. Total Seven units of blood transfused, three preoperatively, four postoperatively. Patient's recovery was normal. Postoperative period remained uneventful.

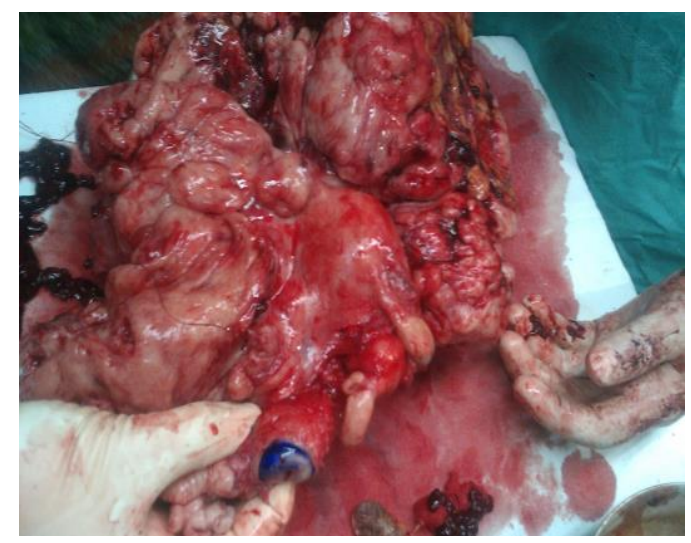

Figure 1: Showing gross examination of tumour with posterior surface of uterus \& right ovary.

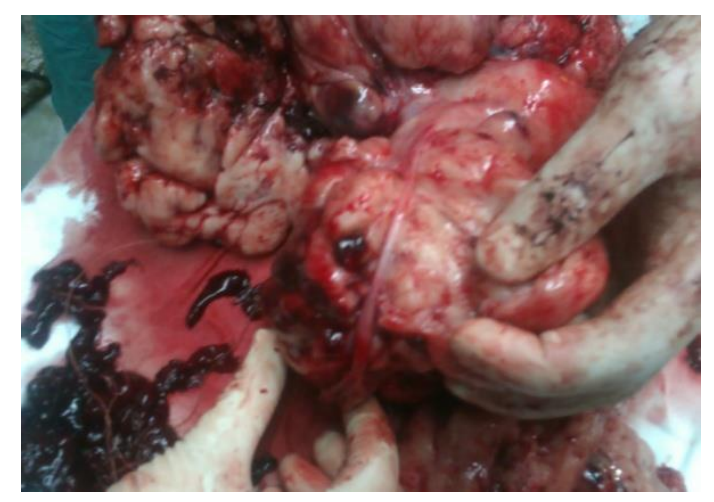

Figure 2: Showing part of anterior wall of uterus with left fallopian tube stretched over tumour. Cut section showed normal looking left ovary encased by tumour.
On gross pathological examination, specimen measured $29 \times 24 \times 9 \mathrm{~cm} \&$ weighed $3.75 \mathrm{~kg}$, large bulbous nodular irregular mass involving the left anterolateral uterine wall. On cutting multiple, circumscribed, grey white solid nodular areas were seen in the wall of the uterus. Both the tubes and ovaries were identified, were normal looking.

Microscopically, the wall of the uterus showed round to oval spindle shaped cells arranged in nodules \& sheets. Cells having pleomorphic bizarre nuclei with prominent nucleoli were seen with areas of necrosis. Mitotic activity was increased. Tumour was infiltrating into the cervix. Both ovaries were unremarkable. There was no infiltration of the omentum by the tumour tissue. Features were suggestive of endometrial stromal sarcomaUndifferentiated type (UES). Post-operative patient was given 3 courses of radiotherapy. On follow up visit after 6 months, she is fine.

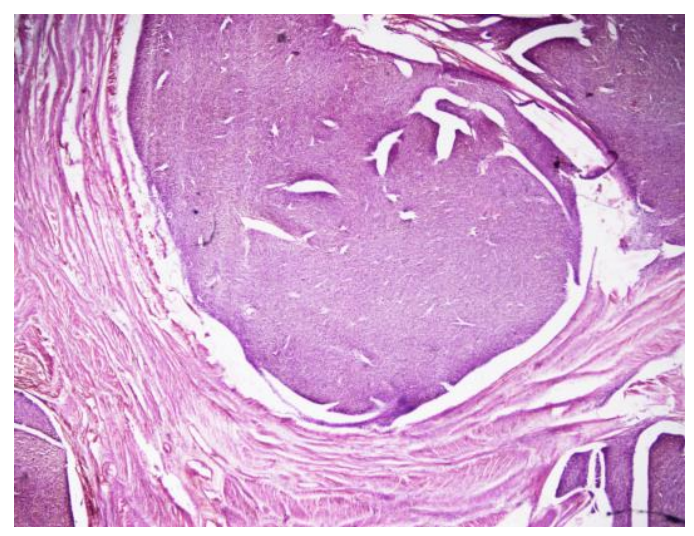

Figure 3: HPE showing nodules which contain spindle shaped cells with round oval nuclei, cells showing nuclear polymorphism. Cells are infiltrating myometrium. Nodules show pushing borders.

\section{DISCUSSION}

The origin \& biology of tumour is poorly understood. Its seen that a recurrent chromosomal translocation $\mathrm{t}(7 ; 17)(\mathrm{p} 15 ; \mathrm{q} 21)$ occurs in ESS. Even normal endometrial stromal cells express this fusion gene showing that a prosurvival gene in normal endometrium somehow subverted to become proneoplastic. ${ }^{2}$ The exposure to unopposed oestrogens \& polycystic ovarian disease also have some role in pathogenesis. ${ }^{3}$ Our patient had only one child \& took some treatment of infertility irregularly but she has no record of type of treatment.

WHO Classification-2003 shows that Endometrial Stromal Tumours are of 3 types. ${ }^{1}$

a. Endometrial Stromal Nodule (ESN)

b. Low Grade Endometrial Stromal Sarcoma (LGSSS) or ESS.

c. Undifferentiated Endometrial Stromal Sarcoma (UES) 
In this classification, the differentiation between low grade \& undifferentiated tumours is not made not on mitotic count but on the basis of nuclear pleomorphism \& necrosis.

Our patient had undifferentiated endometrial stromal sarcoma.

The clinical presentation of ESS is abnormal uterine bleeding, pain abdomen, may be asymptomatic, (25\%). Our patient was postmenopausal, presented with abdominal enlargement, pressure symptoms \& pain abdomen as the tumour was growing outwards from uterine wall $\&$ was measuring $3.75 \mathrm{~kg}$.U $/ \mathrm{S}$ is not reliable for diagnosis. MRI may be useful by presence of bands of low intensity signals within areas of myometrial invasion. CD 10 a cell surface neutral endopeptidase has been shown as positive in ESS differentiating it from leiomyoma which is negative for CD $10 .^{4} \mathrm{ESS}$ is always positive for oestrogen $\&$ progesterone receptors.

Standard surgical treatment is total abdominal hysterectomy with bilateral salpingooophorectomy. Only postoperative observation is required for stage 1 . Postoperative HRT is contraindicated as the tumour is oestrogen \& progesterone receptor positive. ${ }^{5}$ For stage II to IV/recurrence/unresectable tumour, post-operative hormone treatment or radiotherapy is indicated.

\section{CONCLUSION}

ESS is a rare tumour, optimal treatment regimens are difficult to formulate as randomised clinical trials are not conducted. Late recurrences even after 20 years are seen so it needs long term follow up.

\section{ACKKNOWLEDGEMENTS}

We acknowledge the help of Dr Sudershan Kapoor, Professor Surgery, Govt. Medical College, Amritsar for helping us during surgery of this patient.

\section{Funding: No funding sources \\ Conflict of interest: None declared \\ Ethical approval: Not required}

\section{REFERENCES}

1. Tavassoli FA, Devilee P. WHO classification of pathology \& genetics of tumours of the breast \& female genital organs. In: Tavassoli FA, Devilee P. Eds. Lyon, France: IARC Press; 2003: 233-236.

2. Halbwed I, Ullmann R, Kremser ML, Man YG, Moud NI, Lax S et al. Chromosomal alterations in low grade endometrial stromal sarcoma \& undifferentiated endometrial sarcoma as detected by comparative genomic hybridization. Gynecol Oncol. 2005;2:582-7.

3. Cohen I. Endometrial pathologies associated with postmenopausal tamoxifen treatment. Gynecol Oncol. 2004;2:256-66.

4. Chu PG, Arber DA, Weiss LM, Chang KL. Utility of CD10 in distinguishing between endometrial stromal sarcoma \& uterine smooth muscle tumours. An immunohistochemical comparison of 34 cases. Mod Pathol. 2001;14:465-71.

5. Grimer R, Judson I, Seddon B. Guidelines for the management of soft tissue sarcomas. Sarcoma. 2010;2010:506182.

DOI: $10.5455 / 2320-1770 . i j r \operatorname{cog} 20140362$

Cite this article as: Kaur AP, Shergill HK.

Endometrial stromal sarcoma: a rare tumour. Int J

Reprod Contracept Obstet Gynecol 2014;3:276-8. 